\title{
Valorização e aperfeiçoamento
}

\section{Marcondes Mundim Guimarāes ( $\left.{ }^{*}\right)$}

A

Secretaria de Pessoal Civil vem desenvolvendo uma politica de valorização e aperfeiçoamento dos servidores civis da Uniāo nos seus diversos grupos e catcgorias funcionais.

Estamos preparando, na Secretaria de Pessoal Civil, as bases para uma reforma completa na administraçāo do pessoal civil da União e, na Câmara IV da Comissão Geral da Reforma Administrativa, estamos desenvolvendo estudos objetivantes da elaboraç̃o de propostas referentes ao Novo Estatuto, ao Plano de Classificação e Funçōes, ao Plano de Previdência e Assistência ao Funcionário Público e ao plano de Formaçāo e Desenvolvimento de Recursos Humanos.

Muitas medidas sem pressupostos bem anunciados, em relação ao servidor público, foram tomadas nestes últimos anos.

Nāo se instituíram, para as áreas de pessoal da Administração Pública Federal, instrumentos com um minimo de consistência, coerência e validade desejadas, o que acabou por promover distorçōes inevitáveis.

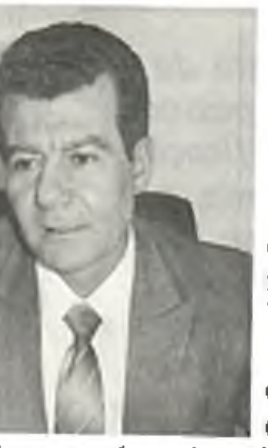

Chegou-se ao ponto de nāo haver um só funcionário público que não esteja reivindicando algo, à vista de decisỏes ambiguas e mal definidas do próprio Governo, inclusive no sentido de beneficiá-lo.

Ao assumirmos a Secretaria de Pessoal Civíl do DASP, a palavra de ordem do Ministro Aluizio Alves foi, exatamente, no sentido de que introduzissemos significativas mudanças na administraçāo de pessoal, especificamente na área de desenvolvimento de recursos humanos, o que vem sendo feito altavés dos estudos que estāo sendo elaborados pelas comissões implantadas para a Reforma Administ rativa.

Tais estudos visam, em última análise, à valorizaçāo do servidor público e à dignificaçāo da funçāo públi$\mathrm{ca}$, a partir da analése de políticas, modelos, instrumentos, técnicas e métodos até agora utilizados, objetivando criar os espaços necessários à consecução de vários objetivos, dentre os quais se inserem o Novo Estatuto do Pessoal Civil do Poder Execulivo, um Plano de Cargos e Salários adcquado às novas necessidades, de modo a
1" Marcondes Mundım Guimarāes é secrelârio de Pessoal Civil do Mınıstérı da Adminıstraçåo e presidenı da Cámara IV da Comissao de Reíorma poder levar a contento o nosso propósito de recrutar, selecionar, desenvolver e manter o servidor dentro da organização, pcrmitindo-lhe o constante crescimento individual $e$, por consegüência, o crescimento da própria Adninistraçāo Pública.

Hoje, podemos registrar que a $\mathrm{Re}-$ forma Administrativa já está em pleno funcionamento.

E isto porque, é nossa opiniāo, uma reforma dessc porte não se faz do dia para a noite; nem se estabelece marco para o seu inicio. Mais importante do que as propostas que estāo sendo elaboradas, nos parece, é o desafio de introduzirmos profundas mudanças nas pessoas a ela ligadas, direta ou indiretamente, sem o que nāo vemos outra forma de torná-la viável. É preciso, portanto, e antes de tudo, que todas as pessoas participem do processo, ativa e conscientementc, para que, juntos possamos encontrar as melhores soluçōes para os nossos problemas.

É com esıa filosofia que os irabalhos estẫo sendo desenvolvidos. Já no mês de fevereiro, a Comissão do Plano de Cargos ultimará as diretrizes que serão encaminhadas para discussāo junto a todos os órgãos e associaçōes representativas de classes pro. fissionais, a fim de colhermos as necessárias críticas e sugestōes calcadas na realidade atual.

Pararelamente aos trabalhos de diagnóstíco e elaboração de propostas concretas, que vêm sendo desen- 


\section{IDÉIAS}

volvidas nas diversas comissões da Câmara JV a SEPEC desenvolve uma linha de ação estratégica, visando, basicamente, a facilitar a aplicação do elenco de proposlas que estão sendo elaboradas.

É o caso, por exemplo, do recente Decreto-lei N. 2280/85, que pretende regularizar a situação funcional de mais de $\mathbf{1 3 0}$ mil servidores ocupantes de tabelas especiais de empregos e as. semelhadas, disfunção que vinha se arrastando ao longo dos anos e que impedia a aplicação de uma política equânime de pessoal, sem falar do descaso que o fato vinha ensejando com relaçāo ao princípio do sistema do mérito.

\section{- O Plano de Classificação de Cargos}

Do ponto de vista da administraçāo de pessoal, o Plano de Classifícaçāo de Cargos representa, por assim dizer, a base vital de sistematizaçāo e ordcnamento das atividades e funções de qualquer organização, devendo, por conseqüência, ser instrumento facilicador de toda a açāo politica de recursos humanos que se prerenda por em prática.

Se atentarmos para a filosofia de concepçāo do atual PCC, a que alude a Lei n. 5.645/70, e para os demais instrumentos complementares de sua implantação, iremos verificar que o mesmo Plano a despeito de contar com pouco mais de 10 anos de existência, já apresenta flagrantes e consideráveis sinais de inadequação aos objetivos propostos quando de sua instituiçāo.

Dentre as principais causas e conseqüências dessa inadequaçāo, podemos enfatizar

a) Classificaçõo de cargos e empregos divorciada das esiruturas organizacionais dos diversos órgāos da Administraçāo, resultante de catcgorias funcionais que, não reflecindo nas classes que compõem sua esirulura a divisão do trabalho da organização que integram, impediam a elaboração de especificaçōes que refletissem as reais atribuiçõcs de cada classe, transformando a Progressão Funcional em mero instrumento de melhoria salarial, sem qualquer vinculaçāo com o crescimento profissional do servidor;

b) Tratamento diferenciado entre os servidores dos diversos órgāos, em face do principio do "gradualismo" introduzido pela Lei no 5.645/70, configurando situaçōes de privilégio, através de obtençāo de benefícios do novo Plano, por grupo de servidores, em determinados momentos;

c) Excessiva rigidez na fixaçāo de lotaçōes, o que resultou na constituição de quadros de pessoal quanlitativamente aquém das efetivas necessidades dos órgãos, forçando a contratação indireta de mão-deobra para recompor a sua força de trabalho, à revelia do sistema de mérito:

Do ponto de vista da
administração de pessoal,
o Plano de Classificação
de Cargos representa, por
assim dizer, a base vital
de sistematização e
ordenamento das funções e
atividades de qualquer
organizaçâo, devendo, por
conseqüência, ser um
facilitador de toda a
ação política de recursos
humanos que se pretenda
por em prática efetiva.

d) Ausência de institucionalização e dinamizaçāo de programas de I reinamento e desenvolvimento de recursos humanos vinculados aos objetivos organizacionais e de crescimento individual, ausência essa evidenciada pela existência de grande contingente de servidores sem a necessária capacitaçāo para o exercício de suas atribuiçōes, culminando na queda qualitaliva e quantitativa dos padrões de desempenho funcional. Essas disfunções, por si só, se nos afiguram suficientes para justificar a implantação de um no Plano de Classificação de Cargos.
É nosso pensamento que o novo Plano deva criar os espaços necessários para assegurar efetivas condições de profissionalização do servidor público, através de sua formação, de desenvolvimento e aperfeiçoamento funcional, em sintonia com os objetivos da organização.

Há que se criar um sistema de classificação de cargos que permita, aos servidores, reais possibilidades de carreira, o que somente será possível, cremos, articulando-se classificaçāo de cargos e estruturas organizacionais, tendo como núcleo conceptual o estabelecimento integral do sistema do mérito, como único princípio democrático capaz de permitir o desempenho eficaz da administração pública.

Impōe-se, para tanto, o estabelecimento de um sistema voltado para o ingresso e para o treinamento permanente, contemplando e amparando as diferenças individuais de pontencialidades e incentivando, de maneira adequada, o comprometimento consciente do servidor com os objetivos da organização e vice-versa. Estas são as linhas básicas que devem nortear a concepçāo do novo Plano de Classificação de Cargos.

\section{Anteprojeto do Estatuto dos Funcio- nários Públicos Civis da Uniāo}

A proposta do Novo Estatuto dos Servidores Civis da União está sendo elaborada a partir das diretrizes aprovadas pela Comissāo Geral de Reforma Administrativa, na Sessão Plenária de $12 / 09 / 85$, e levará em conta a defíniçāo da Organizaçāo da Administraçāo Federal, cujos estudos são da competência da Câmara I da Comissāo da Reforma.

Resumidamente, as diretrizes do anteprojeto do Novo Estatuto aponIam para os caminhos da valorizaçāo do funcionário e da dignificaçāo da função pública, não só através da melhoria das condições de trabalho, como também da ênfase ao sentido da missāo e da responsabilidade social do servidor público, assegurando-lhe condições de efetiva profissionalizacão, por meio de sua formação e desenvolvimento funcional, permitindothe o crescimento na organização, mediante um sistema de carreira. 


\section{IDÉIAS}

Fundamentalmente, o estabelecimento integral do sistema do mérito será a tônica sobre a qual repousarāo as bases de uma administraçāo eficiente, com a qual se legitima a ação política.

O Novo Estatuto deverá, ainda, proclamar a identidade do principio da isonomia, na sua plenitude com o espírito da democracia.

A proposta deverá, também, incorporar as conquistas do funcionalismo, tanto as reconhecidas na legislaçāo, quanto as proclamadas pela jurisprudência administrativa e dos tribunais.

Um único regime jurídico, a partir da vigência do Novo Estatuto, é o cerne de toda a questão e permitirá a adoção de lodas as medidas que se pretende pôr ern prática, ora objeto de estudos na Câmara IV da Reforma da Administraçāo.

Plano de Previdência e Assistência ao Funcionário e à Sua Familia

Insere-se na proposta do Novo Estatuto a implantação de um sistema de previdência e assistência social, extensivo a toda a família do servidor. É um sistema que, pela sua relevância, vem sendo objeto de estudo à parte, confiado à Comissão de Previdência e Assistência ao Funcionário Federal e à sua Familia.

Essa comissāo tem por finalidade elaborar um diploma juridico consolidador de toda a legislaçāo vigente e incorporador das vantagens e benefícios que vêm sendo concedidos pela jurisprudência administrativa e pretoriana, de sorte que possa propiciar aos destinatários, amparo securitário e assistencial condignos.

\section{O Plano de Re1ribuiçāo de Cargos e Funçōes}

Atrelado ao Plano de Classificação de Cargos, o Plano de Retribuiçāo de Cargos e Funçōes está sendo, preliminarmente, objeto de estudos a partir da análise do atual Plano de Salários que, reconhecidamente, não há como prevalecer numa Administraçāo que pretende, sobretudo, valorizar o funcionário e dignificar a função pública, através do sistema do mérito e do principio da eqüidade de tratamento.

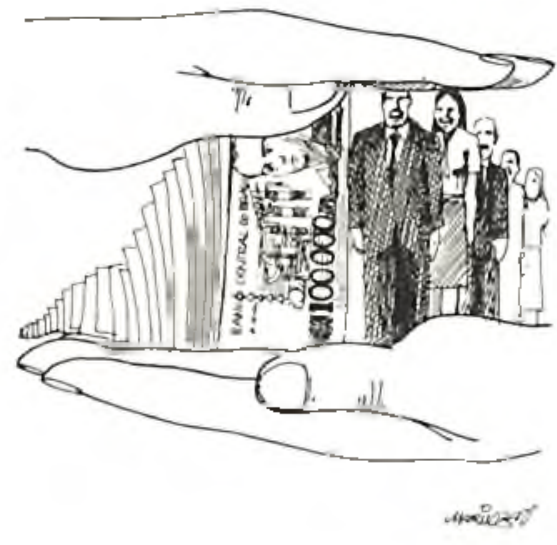

É preciso valorizar o funcionário e dignificar a função pública, através do sistema do mérito e do principio da eqüidade de tratamento. As distorçôes salariais atualmente existentes, privilegiando determinados grupos de categorias funcionais, $e$ as disfunçōes causadas por reposicionamento são, entre outros, aspectos que têm de ser corrigidos.

As distorçōes salariais atualmente existentes, privilegiando determinados grupos de categorias funcionais, o elenco de gratificaçōes e as disfunções ocasionadas por reposicionamentos sem qualquer planejamento global são, entre outros, aspectos negativos que se pretende corrigir.

Outro destaque que se pretende corrigir, no que se refere à diferenciaçāo salarial entre os diversos empregos (atualmente inexistente), é a necessidade de observância das diferencas de potencialidades individuais, como um dos parâmetros para remuneração.

É preciso estabelecer mecanismos que premiem os mais capazes e esti- mulem os menos capazes a uma reciclagem constante.

Formação e Desenvolvimenlo de Recursos Humanos

A capacidade de invoçāo de qualquer organização, seja ela pública ou privada, está intimamente ligada ao desenvolvimento de seus recursos humanos.

Se a proposta da Nova República é a de criar eficácia no desempento das atribuiçōes no âmbito da Administração Pública, como um todo, é necessário, antes de tudo, desenvolvermos um sistema para recrutar e selecionar servidores que se sintam desejados, seguros, significativamente engajados no seu trabalho e verdadeiramente interessados nos objetivos da organizaçāo.

O Plano de Desenvolvimento de Recursos Humanos que se pretende por em prática, em linhas gerais, ultrapassará a conotação de aprendiza. gem a partir da simples transmissāo de conhecimentos, para atingir a dimensão mais profunda da formação de atitudes desejáveis ao processo de integração de pessoas à tarefa e, por conseqüência, às metas organizacionais.

O papel do treinamento que se pretende instalar é aquele que o caracteriza como instrumento de que se vale a instituiçāo para intervir no sistema organizacional, com o objetivo de melhorar sua eficácia.

Será o Plano de Desenvolvimento de Recursos Humanos, antes de tudo, um esforço planejado e consciente, utilizando os conhecimentos existentes, devidamente adequados à nossa realidade, levando-se em conta, outrossim, os valores, as aspiraçōes, os interesses e os objetivos dos individuos, acoplados aos objetivos da organizaçāo.

A partir destas e outras medidas que estāo sendo estudadas na Câmara IV da Comissão da Reforma Administrativa, estarcmos certos de levar nossa contribuição aos pressupostos básicos da Reforma, que, entre outros, ressaltam a restauração da cidadania, a revitalização do serviço público, a valorizaçāo de seus servidores e melhoria dos padrões de desempenho, em benefício da sociedade a que servimos. 